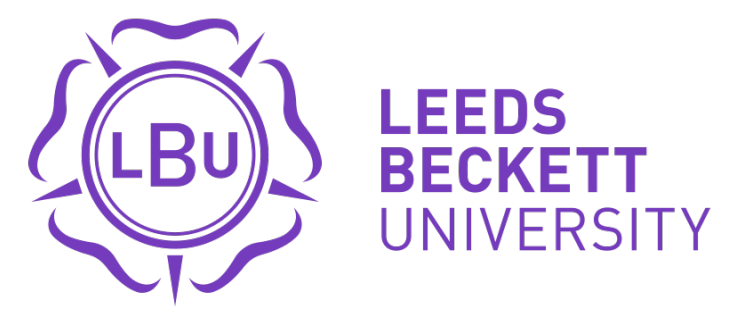

Citation:

Hylton, K (2018) I'm not joking! The strategic use of humour in stories of racism. Ethnicities, 18 (3). pp. 327-343. ISSN 1468-7968 DOI: https://doi.org/10.1177/1468796817743998 Kevin Hylton

Link to Leeds Beckett Repository record:

https://eprints.leedsbeckett.ac.uk/id/eprint/4035/

Document Version:

Article (Accepted Version)

Hylton, K, 'I'm not joking!' The strategic use of humour in stories of racism, Ethnicities, (Volume: 18 issue: 3, page(s): 327-343). Copyright (C) 2017. Reprinted by permission of SAGE Publications

The aim of the Leeds Beckett Repository is to provide open access to our research, as required by funder policies and permitted by publishers and copyright law.

The Leeds Beckett repository holds a wide range of publications, each of which has been checked for copyright and the relevant embargo period has been applied by the Research Services team.

We operate on a standard take-down policy. If you are the author or publisher of an output and you would like it removed from the repository, please contact us and we will investigate on a case-by-case basis.

Each thesis in the repository has been cleared where necessary by the author for third party copyright. If you would like a thesis to be removed from the repository or believe there is an issue with copyright, please contact us on openaccess@leedsbeckett.ac.uk and we will investigate on a case-by-case basis. 


\title{
I'm not joking! The strategic use of humour in stories of racism
}

\begin{abstract}
This study examines the use of humour by Black football coaches in England as a rhetorical device against racism. The paper draws on humour studies and critical race theory to illustrate signs of humour as defence. Research on humour has popularly explored the ambiguities and qualities of humour and in particular joke telling though its use as a foil to stem racial ills is less well understood. Where previous work has focused on explicit joke telling/banter in sport this paper examines how techniques of humour are used in everyday racialised experiences. The use of techniques of humour enable feelings of subordination, and humiliation to be transposed into forms of resistance, while its physiological and psychological benefits can lead to inter-racial relief and catharsis. The paper concludes that techniques of humour remain underexplored as important tools of resistance to everyday racism.
\end{abstract}

Black Coaches, Critical Race Theory, Strategy, Humour, Racism, Storytelling 


\section{Introduction}

This study examines the use of humour in storytelling by Black ${ }^{i}$ football coaches affected by racism in sport. Humour is found in all social settings, though significantly for Lockyer and Pickering (2005) it is not synonymous with comedy and joke telling. Humour has been viewed as a way to ridicule and disempower in a range of fashions. On the other hand, humour in stories offers opportunities to empower and liberate oneself of problems and oppression (Bowers, 2005). For example, Robidoux's (2012; 2004) study of the Kanai First Nations ice hockey team in Canada revealed how stories and the humour within can disrupt the power of racism and historical colonisation (Gunn Allen, 1992; Vizenor, 1994), and in literature viewed as a way to contend with the tragic (Gaggiano, 2005). Watson (2015) goes so far as to say that the subtleties of humour are significant in the human experience and that we ignore its effects at our peril.

Research on humour has popularly explored the ambiguities and qualities of humour and in particular joke telling though its use as a foil to stem racial ills is less well understood. In contrast, it is argued here that humour can be used to handle and disrupt unpalatable experiences of racism. Such techniques facilitate the sharing of cultural wealth which typically informs the cultural capital to navigate and resist negative experiences (Yosso, 2005). Though racism and racial humour have been evidenced as pernicious aspects of sport, the use of racialised humour as offence and defence is complex and requires further examination. 
The study aims to explore how humour techniques work to resist the impact of racism and in order to capture this the research revolves around three main questions: 1) How is humour used by Black coaches as a technique in stories of sporting oppression? 2) How does humour challenge their negative experiences of racialisation in sport? And, 3) What do their stories of racism tell us about sport? Rather than an analysis of racist humour, this study enlivens the debate on how humour can console/include and deflect/exclude for Black and minoritised coaches in sport. The paper begins with a consideration of how humour has been incorporated in the sport literature. It then moves on to outline key theoretical themes drawn from humour studies that underpin the critical race approach adopted here. Following this the methodology becomes the precursor to a critical presentation of the findings from a focus group of Black football coaches in England and their stories of racism in football. The conclusion draws out how humour can be recognised in storytelling and how it can strategically empower the voices of Black coaches.

This paper is not used to specifically define humour or what is funny, which Ostrower (2015: 184) suggests is experienced when intellect (wit); emotional (levity or gaiety); and physiological (laughter or smiling) coalesce, rather it illustrates signs of humour in how Black coaches recount racialised events (Andronoviene, 2014). These signs of humour are more than joke telling and anecdotes about funny events but stories that apply the strategic use of humour in ordinary everyday events. Humour in the context of everyday racism in sport emphasises Delgado's notion of humus the root word for 'humour' to bring racism low and down to earth (Delgado, 1995: 61). By focusing on everyday racism in 
football/sport the paper further reveals a) the way it directly affects Black and minoritised individuals b) racism's variegated forms, and c) strategies used to lessen or disrupt racism's impacts.

\section{Sport and humour}

Though Snyder (1991) lamented the relative lack of interest in sport and humour there still does not seem to have been a significant shift in its allure (Snyder, 1991). The literature on sport and humour is scant though what has been written has an emphasis on more overt and predicable themes that include the place of jokes and banter (Snyder, 1991; Burdsey, 2011), sexism and gender (Anderson, 2015; Shaw, 2006), sport cultures and team cohesion (Sullivan, 2013). Where humour has been explored in relation to racism in sport there has been an insightful focus on the mitigation of racism and bigotry as jokes or disparagement and superiority (Reid, 2015; Burdsey, 2011; King, 2006).

Snyder (1991) argued that humour in sport has the potential to reveal previously unexplored phenomena. He revealed the commonalities in descriptions of humour that have at their core types of discontinuity or incongruity that suggest more than one way to read an event. For Snyder (1991), what makes something humorous is to describe a scene so that the audience understand the alternative reading(s) and 'get it' in what Snyder (1991: 119) describes as a resolution of conflicting images. Like Sullivan's (2013) analysis of sociable traits in teams, Snyder also considered playful behaviour when he considered how humour could be used as building blocks for sport team cohesion. Similar to Anderson's (2015) criticism of sexism and gender in sport he also explored humour as superiority and 
disparagement. Where humour has been explored in relation to sport themes that examine team dynamics and character traits (Sullivan, 2013), sexism and gender relations in sport cultures are popular topics (Anderson, 2015; Shaw, 2006).

In Reid's case, humour was examined to explain how it could be used to deny intolerance or justify the discriminatory comments about the sectarianism of the Celts and the Irish. King (2006) had similar concerns about the Anti-Asian (American) racism in sport. Though not the focus of this study, in both Reid (2015) and King's (2006) work racist perpetrator(s) have attempted to lessen the impact of their actions by trivializing them as humour. Consequently, Clarke (1998) argues that jokes can act as the 'velvet glove' of racism, as they perpetuate previously unpalatable myths in a more acceptable way in what Ford et al (2015) term 'disparagement humour'. Contrary to this paper, Snyder (1991), as with the other studies of sport and humour mentioned thus far, focus primarily on events that were deemed to be humorous that would then enable a critique to explain why they were problematic or viewed as such.

This paper also builds on Burdsey's (2011) work that illustrates how racism in sport is manifest through a plethora of racial microaggressions in the everyday. Microaggressions that emerge through personal, institutional and environmental factors; microinsults, microassaults, and microinvalidations (see Sue, 2010). Burdsey's (2011) concern with the place of humour in masking the presence of racism in sport emerges from a need for those in sport to move beyond common conceptions of racism and discrimination in sport as being things of the past. The 
consequence of adopting such a passive stance is to allow racism to thrive, unfettered and unchallenged.

\section{Theories of humour}

Bowers (2005) describes using humour as a form of communication that can have the effect of i) an ethnic glue, ii) a celebration of survival, and iii) a release of intercultural and interracial tensions. Similarly, Wilkins and Eisenbraun (2009) summarise the physiological uses of humour as coping mechanisms. In relation to extricating something light out of stressful situations, Wilkins and Eisenbraun (2009) argue that through humour everyday struggles and disappointments become easier to manage and overcome. Humour is also seen as a way to speak truth to power (Andronoviene, 2014) or to shift situations from the negative to the positive. Weaver (2011a: 27) considers the shifting of negative to positive using a technique of reversing the negative effects of racism. Yet he goes on to state that, The question of whether the release of racial tension through humour is problematic has received little attention.

Humour can often be ambiguous and deliberately prone to a range of readings. This ambiguity reflects what has been described as its polysemic nature, as irony, context and a plethora of meanings are spelled out with Weaver's (2010a) use of a 'rhetorical triangle'. Weaver (2011b) draws on ideas originating from Aristotle and developed in critical discourse analysis by Richardson (2006) of the arguer (teller), audience (receivers), and argument (story). In addition, it is commonly stated in humour studies that there are three theories of humour (Incongruity, Superiority and Relief) (Weaver, 2011b; Critchley, 2002; Ostrower, 2015). I draw on each 
theme opportunistically in this study as there is such a complementary overlap across them. The idea of Superiority can be seen where some of the stories of racism in this study resonate with ideas of humour that argue the perpetrators of racist acts are subverted and notions of superiority over them displace feelings of anger, ambivalence or hurt. Clarke (1998) explains that humour can cause two people to laugh for apparently different reasons. He states that receivers can sometimes laugh because of the sense of superiority ensuing from the teller while the teller may laugh because of the repressed emotion and tension that saves on the psychic stress of such experiences. Superiority and relief can be initially viewed as functions of humour whereas incongruity suggests more about the form humour takes.

Theories of Relief often draw from Freud's (1991 [1960]) work on feelings of release that if anxiety were not dispatched this way it would cause some psychic harm to the victims of racism. Weaver (2011b) argues that it was Aristotle who first made the links between humour and Incongruity, yet many argue that it is incongruity that significantly contributes to the structure or techniques used in the sharing of stories to evoke situations. Some of these situations can be nonsensical with a view to subverting an event to emphasise humour and therefore the teller's preferred reading of a story (Critchley, 2002). Weaver (2011b) explored incongruity in relation to how racialised groups reversed racist words to take away their power by delivering a reverse semantic effect. For incongruity to work there must be a juxtaposition of two or more objects that lack consistency, harmony, propriety or conformity (Berger 1998, cited in Weaver, 2011b: 18). Critchley (2002: 4) goes on to affirm this in relation to jokes: 
In order for the incongruity of the joke to be seen as such, there has to be congruence between joke structure and social structure - no social congruity, no comic incongruity.

Weaver (2010b) uses the term ' resistance humour' to describe a discourse positioned in opposition to the perceived racism perpetrated by others, yet this is only partially my aim. Though I am concerned with how humour is used to ameliorate experiences of racism I am not solely concerned with the specific use of racist jokes or banter as starting points for rhetorical subversion. My aim is more broad and encompassing. This paper is concerned with the everyday strategic use of humour techniques in storytelling given that the recourse to humour presents an opportunity to see it working in a way that is less trivial in nature for those affected by racism in sport (Clarke, 1998).

\section{Methodology}

This study explores the rhetorical dynamics of humour in storytelling with Black football coaches in England as they share experiences of everyday racism. Delgado and Stefancic (2001: 39) describe the storytelling of Black and minoritised ethnic groups as a way to 'open a window onto ignored or alternative realities'. Where dominant groups have little understanding of how minority groups experience their sport then storytelling can help to facilitate understanding by 'bridging the gap'. In this study the techniques used to share stories of racism become the focus for the analysis of the role of humour. 
Stories can reveal a different everyday reality to the one that is 'known' thus revealing 'unknowns' for a new critical consideration of issues. Stories can also give voice, or as hooks (1989) might suggest 'teach to transgress' and make visible those that have historically been marginalised. In relation to notions of humour as resistive the Black coaches' focus group offers a chance to explore Delgado and Stefancic's idea of 'counter storytelling'. Counter storytelling is sometimes used to illustrate the destructive function of dominant discourses by offering an alternative reading. For example, in one of the few studies of humour in sport, Robidoux (2012) used storytelling in his research with First Nation hockey players to demonstrate how their humour can be used better to understand their racialised context. He used illustrated humour as a technique of empowerment and relief of racial tension.

As Delgado and Stefancic $(2001 ; 1999)$ suggest, stories should be able to name and challenge forms of oppression and prejudice. Therefore, stories should also be capable of contributing to their dismantling. Bowers (2005) describes the power that can accrue through storytelling and the storytelling process often afforded to those who may have been in less fortunate social positions. Through using elements of humour it can be seen how Black coaches reimagine protagonists and everyday forms of oppression in sport as part of their storytelling. It can enable a demystification and disruption of oppressive forces while enhancing the wellbeing of those that have suffered from such processes. 
Methods and Analysis

In this study nine Black and minoritised ethnic coaches were included in a pilot focus group to facilitate the sharing of experiences of racism in sport. Each of the coaches self-identified as Black and were part of a network for established, qualified and experienced Black football coaches in England. Access was facilitated through a coordinator and each coach voluntarily consented to contributing to the study. Focus groups have been very successful in putting a group of acquaintances at ease and enabling subject matter, guided by the researcher, to develop ideas that even the researcher may not have initially anticipated (Gratton and Jones, 2004; Gunaratnam, 2003). Participants, known to each other, are more likely to feel relaxed especially where the subject matter can be sensitive. The focus group was made up of predominantly African-Caribbean men [7 Male] and South Asian [2: $1 \mathrm{M} / 1 \mathrm{~F}]$ coaches.

The coaches were introduced to the aims of the focus group to share and explore experiences of racism in football. Humour was not divulged as an objective of the study to ensure that the group was not led toward attempting humorous or comedic anecdotes. This approach enabled any techniques of humour within the storytelling to emerge naturally. Pseudonyms are used throughout. The focus group was digitally captured with a camcorder and boundary mic voice recorder. Perakyla (2005: 510) suggests that where data is more 'naturally occurring' as in focus groups there is a chance that the way the interaction is recorded may ignore or marginalise key pieces of data. It is recognised that in the telling of stories, the sharing of instructive and sometimes ambiguous tales, the text does not necessarily share the body language and non-verbal cues that occur in social settings. In 
addition to a field diary, this multi-modal approach favoured by ethnographers offers a richer and deeper quality of data that will enable a more sophisticated examination of the interactions in the focus groups.

Critical race scholars have been conscious of the contradictions between action and behaviour and the need to represent what is happening from the point of view of racialised actors (Duster et al., 1999). This has led to research embracing social justice and transformation that challenge established ideologies in sport (Hylton, 2012; Carrington, 2010). Privileging the Black voice through a plethora of techniques has become popular in CRT research, especially storytelling and counter storytelling methods as ways to 'hear and understand the voices' that are rarely heard (Bell, 1992). This paper presents rich description in an extended theoretical account to get at what Charmaz argues goes beyond the overt to the 'tacit, liminal, and the implicit' (2005: 513). A grounded theory approach more closely aligned to the work of Charmaz was used to allow the major themes from the telling of stories to emerge. Perakyla (2005) describes a grounded theory approach as a set of guidelines that lead researchers to build mid-range theories through systematic data analysis and the reworking of possible readings of data and development of key concepts.

To aid this process of analysis I draw on use of the 'rhetorical triangle' that considers the significance and influence of the arguer (teller), audience (receivers), and argument (story) (Weaver, 2011a: 5; 2010a). This enables a more convenient examination of the context of the storyteller, the audience and the content and rhetorical structure of the argument. The arguer, the audience and the argument is 
the dynamic structure within which the 'humorous' is explored. In addition, Berger's (2013) typology of forty five techniques of humour enabled an ordering of approaches to storytelling that revealed an alternative perspective on the content of the stories shared (see Figure 1). Other factors influencing the reading of each story included non-verbal communication and style of deliveryii. The place of humour within this telling is where we now turn.

\section{Figure 1 Here}

\section{Findings}

These findings reflect themes emerging from the coaches' focus group. They include stories of betrayal, White privilege, violence and multiple forms of racism. The group spoke across a large oval table in a room where they regularly met and therefore were comfortable in the setting and in each other's company. It is also imperative to note that some of the stories were humourless in the context of Berger's (2013) typology, Weaver's use of the rhetorical triangle (2010a, 2011a) and the three major themes of relief, superiority and incongruity found in the humour studies literature. In this context stories were chosen based on their potential to enable an examination of these signifiers of humour in a natural social environment. However, the first story shared by Kurt did not use humour. Kurt's 'matter of fact' telling of his experience was indicative of a number of the conversations in the focus group as highlighted by Gary who stated that: 
But I think when you tell stories, your life is a story of fighting against racism, so to pick out a story is difficult, it just seems like a conveyor belt of a process, dayby-day, moment-by-moment. And you try to think about how do I stay in my story and keep my sanity about who I am actually as a black person?' [Emphasis added].

It was neither easy nor straightforward for members of the group to pick experiences to share. Many of the experiences were purely statement of fact and delivered without any discernible trope of humour. However, Gary reflected on broader issues in relation to the Black experience in the UK when he stated that it was difficult to choose one example from a plethora of others. In some ways, the mundanity of some of his everyday experiences did not seem to him to add up to a 'big' or interesting story. Awareness of microaggressions inevitably requires a critically informed 'race' consciousness thus making them highly slippery and difficult to articulate. Nevertheless, all of the stories were useful and how they were shared was instructive.

Kurt was the first to break the ice and speak and was choosing his words so as not to name names or implicate anyone in the football establishment. He told the group about how he felt he had been racially discriminated against in a high-level coaching assessment. He was unsure if it was due to his Jamaican accent or his Black skin though he knew there was a problem because the White coaches ignored him when it was his turn to do his coaching assessment. Kurt felt that no one wanted to take part in his session. With some emotion and indignance he went on to say: 
And when it was my time to do my session, no-one - $\underline{\text { no-one }}$ was willing to participate, and the assessor said to them 'You must participate in all of the session" ... and you tell me say no one participate in mine?! Not one person participate [sic]. And, to tell you the truth, I was going to say something and I looked at myself, and I said 'What does it matter?'

Kurt's use of the turn 'what does it matter?' suggests more than ambivalence or resignation on his part. It hints at the everyday weariness of negotiating subtle and ambiguous racism that cause people like him to calculate the potential for success were they to challenge such behaviours. 'What does it matter?' in the context of these coaches seemed to resonate with them as their non-verbal communication through body language and the occasional nod signified acceptance, more than disbelief, that racial discrimination occurs in this way in football. In a more diverse group there might have been some scepticism about the meanings of the White coaches' behaviour, whether Kurt had misinterpreted the situation, or perhaps that it was a one-off scenario. Yet there was no question in this focus group, from any of the coaches for clarification or qualification, which would suggest that Kurt's story is one that reveals part of the lived reality for these Black coaches.

In following Kurt's sharing, Bucky [Asian Male] started with an example of what Freud (1991 [1960]) would describe as relief [or release] through humour. This took some tension out of the atmosphere and offered some indication of how humour can be used as a form of resistance. Following Kurt's serious claims of racism, Bucky stated: 
I can call this little section 'name, shame and blame' if I really wanted to. I won't name them, but I'll certainly shame them and I'll definitely blame them!

Bucky began brightly with what Berger (2013) would describe as wordplay and a tone that gave the impression that he was about to tell an intriguing story. He outlined a situation at a UEFA Biii coaching course where the coach leading the sessions over the whole fortnight chose to call him Gunga Din in reference to the colonised and exploited Indian character in Rudyard Kipling's poem of British rule in India. The use of the term Gunga Din in this context emphasises the Coach Assessor's confidence that the use of racial epithets in the company of other predominantly White coaches was acceptable. Maybe the White players were afraid to challenge the authority of the coach educator and unwittingly reinforced Kurt's experiences of racism in football? Kurt's experience also resonates with King's (2004) research into 'race' and football that highlights the expectation that Black coaches relegate their own identities to fit into a privileged culture of whiteness. He offers more on this story and draws on some tropes of Weaver's (2010a) rhetorical triangle in the story (argument), the way he told the story (arguer) and the coaches' reception of it (audience) to make his point:

This was 1996, and he kept on going 'Oh, Gunga Din, can you do this, Gunga Din, can you do that.'! Well, the way I saw it, OK, is that I wanted to get the award. I didn't feel at that point in time... Everyone else found that, you know, it was slightly humorous, everyone had a little laugh about it, OK. But it's like anything... I felt that at that point in time there were two ways I could have dealt with it. I could have not turned up and not finished the course. I could have carried on, got the award, and dealt with it afterwards. But I was slightly naïve, even then, to be honest with you

Unlike a traditional joke the use of humour in the sharing of stories of racism does not necessitate laughter or spontaneous applause. Bucky's story was not only a descriptive sharing of a racist experience that was recognized as so in the focus 
group, but it also repositioned him within the story because he took the moral high ground in refusing to react to the blatant racism of the coach assessor or the 'banter' in the group.

Bucky's re-envisioned superiority to the racist coach enabled him to share how racism can not only manifest itself but also demonstrate how others condone and reinforce it through acquiescence. While doing this he also offered an argument for when to navigate and resist racism in football. On balance, he did not see a benefit to openly resist the coach educator, or group racism, as it would have affected his future income. Yet it is clear for many in their research into racism and whiteness in football such as Jones (2002) and (King, 2004) that 'getting on' comes with a price. The price of not challenging such engrained racism is that it maintains the hierarchies and boundaries between in-groups and out-groups, stereotypes and racialised differentiation. Further, the antiracist potential to 'rob commonsense racism of its power' is also lost in those moments (Hynes and Scott, 2015: 2).

Bucky's story about football coach education, partially enabled by tropes of humour, is brought to the meeting room and shared in the way Yosso (2005) would describe as cultural wealth, a type of under-researched form of cultural capital. It is likely to have assisted others in the room to make decisions in the future that would help them, through an increase in what Yosso would term 'navigational' capital, to manage football coaching culture more pragmatically (Yosso, 2005). Further, with all of the caveats of acting/not acting, the coaches may also have an improved understanding of how to use their 'resistance' capital more strategically; 'when do I push back, and under what circumstances?' 
At this point in the paper it would be no surprise for readers to expect more traditional signs of humour in these stories. Hence it is worthwhile reiterating that none of the stories incorporated joke telling, and that most of the stories required a theoretically informed reading. There were a number of stories about experiencing racism though a number did not draw on tropes of humour. Bucky's story followed Kurt's and yet the next one, Lanky's, drew on more obvious tropes of incongruity, superiority, absurdity and even a comic chase [see Figure 1]. He began his story by setting out a scene when he was playing at a high level. As an ex-professional player he talked about a game where a spectator ran onto the pitch:

I was playing for Axxx City against Bxxx United at [stadium], and we were winning the game... And you know as with most games, five minutes to go, knackered, away from home, decide to go down, bad ankle, you know, just to get a breather, just to slow it down, do you know what I mean? Waste time. And everyone knows what you're doing. But then obviously getting up ... as the physio was dealing with me... out of the corner of my eye... see a fan running onto the pitch... shouting 'you black bastard!, you black bastard!, you black bastard!' So I'm kind of like...'OK, what do I do now!?'

Lanky's turn to two of Berger's (2013) comic tropes of absurdity and a chase scene masked the grievousness of this emotionally hurtful and potentially dangerous and violent experience; not least because he was caught out while feigning injury, which offered a more obvious comic twist. It also acts as another example of the burden of abuse that Black players have to endure relative to their White counterparts (see Holland, 1997). This coupled with Lanky's distinctive, cheeky regional twang meant that his sociable, almost staccato delivery distracted the audience from the more heinous elements of his story - he was attacked by a racist. After describing how the fan was intercepted Lanky reflected upon other professional Black players' experiences of abuse and the need for him to do his 
utmost to resist such occurrences. In beginning with that initial comic release of tension he finished with a sharp political point that emphasised the theme of superiority:

'Do I report it or do I just let it go?' ... So I just said to myself - and remembering that the guys before me and what they'd had to go through, 'I can't not do this.' And it was kind of the loneliest journey, you know, going to court by myself, going up to Bxxx by myself to give evidence... The guy sent me this letter apologising to the staff and all that kind of stuff... as they do. But in my brain I was going 'No... I have to make a stand here!'

Turning back to Bucky: he recounted how after achieving success in the racially charged UEFA B award he encountered another type of racism that reflected the broader social stereotyping of South Asian men, while at the same time reinforcing the myths of racial stereotypes in football. Bucky's $2^{\text {nd }}$ example is replete with Berger's use of humour techniques that include absurdity, before/after, disappointment, embarrassment, exposure, ignorance, and sarcasm. His experience of racism proceeded thus:

I got the UEFA B, and he [Coach Educator] also said 'Within a year you can maybe go for [the] A License.' So then I left it a couple of years and then in [Year] I got the sponsorship to go for the A License, and the open prison that is Lilleshalliv was beckoning. I suppose... driving up there, I was told it was a 9.30 start. I left my house, I felt, in plenty of time. But there weren't really many satnavs at that time [...] so I was kind of running late. And I kind of got there... Once I got into Lilleshall I couldn't find the car parking. I got a car parking space, probably about five minutes late. Rushed out. Ran down to reception. I had all my paperwork with me. Got to reception, said to the lady 'I'm Bucky Fizzan, I'm doing the A License.' [receptionist said] 'Yeah, it's the introductions, second floor.' Strolled up to the second floor, knocked on the door - 'Coach Educator'. Opened the door. And the first thing he said to me was 'No one called a taxi here, mate, you're in the wrong place!' And I brought out my papers and said 'I'm here for the A License, my name's Bucky Fizzan.' And he went 'Oh, sorry, sorry... misunderstanding.' 
The audience reception was impassive and taciturn in response. There was a collective edginess across the room as Bucky spoke accompanied by the occasional nod of recognition, visible shock or shake of the head at key moments of the story. The coaches were respectful and seemingly disgusted but their demeanor was one of awareness and acceptance, if not accepting, of football culture. A football culture that in their research on the experiences of elite level football coaches Bradbury et al. (2015) state is continually experienced through stereotyping and notions of unsuitability.

Simon was the next coach to present the group with a story, though this one was closest to a traditional comic anecdote. Yet, once the comic markers are removed that make the story more palatable and less traumatic for him to share, and the group to hear, it reveals a horrific personal story that would leave most feeling traumatised and vulnerable. Simon was a big, confident charismatic man who launched into the telling of this story as though he had shared it a few times. However, Simon had not told his children this story, which says something about the severity of its content. He uses humour techniques that draw on earlier theories of incongruence, while Berger's (2013) humour techniques are heavily represented by the use of absurdity, before/after, bombast, burlesque, disappointment, exposure, ignorance, impersonation, insults, irony, mimicry, wordplay, ridicule, and unmasking, that coalesce into this one story of betrayal, racism and ultimately superiority:

I'll have a go. I'm Simon Fairweather. Despite my youthful good looks I'm actually [age]... And I was happy to support - don't know really why, but I had to support a team called Axxxxx United. I went to watch them in the '80s, and they were the most vehemently racist group of supporters you've ever heard... 
This is the story that I'm telling this group. I haven't told this to my kids. But I remember going to watch Axхxхx play Wolves away in the Cup. We lost one-nil. Before the game, there was loads of bother, and there were loads of Wolverhampton lads - black, white and indifferent - chasing Axxxxx supporters, because Axxхxx had a big National Front there. I went with this lad - and this lad now... I can name him, he's actually a [Job/Location]. And he was a good guy, a mate of mine, I'd known him for not that long, but I'd known him for a while. And I was 17, 18. Twenty minutes into the game, we're in the away end, the Axхххx supporters, and the whole away end started singing 'We hate niggers' and as I looked to my right, they're all singing it - I looked to my left... but the guy I was with was singing 'We hate niggers.' The bit I remember was the veins coming out of his neck...he was singing it with such venom! [...] Two hours later, he was at Wolverhampton train station, shitting himself and holding on to my arm because I was the nigger that was going to keep him alive... the reason I tell the story about Axxxxx is because two hours, he hated niggers and at Wolverhampton train station, 'Protect me Simon, you're a big black guy, they won't hit you!'

Here Simon shares an anecdote that emphasises the banality of bigotry, and the ambivalent ignorance of a 'friend' who in a matter of hours openly shared what Hughey (2011) and Picca and Feagin (2007) describe as the backstage talk of White people. Simon's friend was able to enjoy the security of whiteness in the hostile football arena while thoughtlessly subjugating his friend in what one might perceive he would see as harmless banter. Muller et al. (2007) argue that when soccer fans who are not labelled as racists commit racist acts they often deny accountability. As a result, the burden of claiming that racism took place fell on Simon. Simon's 'friend' later revealed a more vulnerable frontstage away supporter identity that emphasised the contingent nature of embodied identities when he pleaded for help from the racialised body that he earlier denigrated. Sullivan and Tuana (2007: 1) would describe this behaviour as an ignorance of injustice and an 'obliviousness to racism and white domination'. 
Following on from Simon's bizarre experience the group discussed notions of hegemony [if not in those terms], internalised racism and collusion in Black communities, in addition to issues of racialised and gendered identities. Yet during all of this, an example of humour as relief emerged as we approached the end of this, sometimes tense, group conversation. As Bob, reflected on his position as an equalities tutor an exchange ensued that not only drew on a number of Berger's humour techniques, but also engaged notions of exaggeration, ridicule, stereotypes/irony and facetiousness.

At this point, Bob was about to share his experience of equalities tutors in football whom he argues struggled to keep their racism shackled. He went on to make statements like, it is really frightening to hear quite overt racists kind of contorting themselves to take on the new language. And how during the training I was still getting racist remarks from other equality tutors...And yet before completing the preamble to his story Bob engaged in what could be described as the most obvious light-hearted, good-humoured exchange. This exchange with a number of the coaches enabled a sense of release for the group through the pressure valve of laughter. It was a distraction from the serious nature of the topic that reinforced the cohesion of the group through a flurry of dialogue that lifted the atmosphere to enable a challenging reality to be shared:

Bucky I think you did me as well, Bob [Assessed him as a tutor].

Bob Oh, I done your assessment? Yeah.

Bucky You failed me!

[Laughter and comments]

Bob Do you know what? I'm going to put my hand up to that one...Bucky was totally crap.

[Laughter] 
Bob I only passed him...

Because he's Asian?! [interrupted, Suria, S. Asian Female]

[Laughs]

Bob We colluded together. That's obviously what we will do when we get into positions of control...!

[Laughter]

This was the point in the discussion where there were more obvious concerted attempts at recognizable humour than at any other time in over an hour's focus group. It is reasonable to suggest at this point in proceedings that relief from the whole process was being experienced across the group. This exchange was at a point in the discussion when the group had relaxed in each other's company and after some anxiety had built up to this opportunity for more traditional banter inbetween the storytelling. Yet these quips were clearly drawing on good natured sarcasm while the satire in the exchange with Suria alluded to White backlash notions of the Black creep into the upper echelons of sporting organisations while the allusion is established using techniques of incongruence; facetiousness and stereotype.

\section{Conclusion}

With an application of Berger's typology, the rhetorical triangle and humour studies themes of Incongruity, Superiority and Relief a nuanced understanding of the rhetorical dynamics of this focus group emerge (Berger, 1995; 2013; Weaver, 2010a; 2011a). Depending on the context for these Black coaches, techniques of humour may indeed entail a relief from tension, psychic harm, and a strengthening of a group...equally it may signify resistance to suffering. Reid (2015: 231) describes humour here as giving serious issues voice and status. hooks' (cited in McNair, 2008: 204) description of language as action, as resistance and struggle is 
illustrated as humour enables some often taboo subjects to be raised. The coaches' stories were not systematically infused with everyday humour though the strategic use of these techniques hinted at a celebration of survival in the face of adversity (Bowers, 2005).

A reading of the coaches' narratives emphasises Ostrower's (2015) observation that humour emerges when we experience negative emotion. In this respect it is argued that humour can be used as a device for 'serious purposes', it can also heal and hurt as we saw in Kurt's opening story and Bucky's distressing ‘Gunga Din’ experience (Mulkay, 1988). We also saw evidence that stories told by underdogs are frequently ironic or satiric (Delgado, 1995: 61). One of these purposes is for out-group realities to circulate as a counter reality (Andronoviene, 2014). It could be argued that the coaches' stories assisted each other to become more conscious of how to navigate a racist sport. In some cases these strategies were implemented for survival, in fear of being cast as anti-social, 'humourless', or even unemployable. These lived experiences are recounted in a rhetorical triangle that repositions the teller in what have been humiliating, traumatic, and disempowering situations. Perpetrators are also repositioned as the teller is empowered for the benefit of self and the audience. Inferiority, subordination, and feelings of oppression are turned into superiority and everyday social arrangements are made incongruous, and racialised difficulties are at least partially ameliorated as strategies for future microaggressions are shared.

In relation to many of the stories, once the signs of humour are taken away, they reveal microaggressions recognizable as insults, invalidations and assaults 
(Burdsey, 2011). For example, Bucky's taxi driver and Gunga Din incidents, Simon's debilitating National Front story, Lanky, Kurt and Bob's experiences that without tropes of humour would affect the audience and the teller's anxieties, feelings of marginalisation and oppression.

The use of humour as defence against the multiple effects of racism has the potential to empower the Black coaches' voices, transform their felt experiences and how they see themselves and others, and engage them in sharing cultural wealth. The polysemic nature of the coaches' stories also enables them to retain a double meaning requiring of interpretation as serious content is maintained regardless of the level of the delivery or tropes of humour within. This study reveals a significant need for further explorations into humour studies as a tool to understand how racism is resisted by Black and minoritised ethnic groups in sport. The import of such a research agenda for the future direction of humour studies in sport should be clear as we touch upon the subtleties of humour (Watson, 2015). It appears that humour is neither 'trivial' nor 'playful' in the negative, and yet we cannot ignore how it has been used here in a plethora of ways to act as resistance to racism in sport. 


\section{References}

Anderson P. (2015) Sporting Women and Machonas: negotiating gender through sports in Argentina, 1900-1946. Women's History Review 24: 700-720.

Andronoviene L. (2014) The Practice of Humour and our Spirituality: Some Reflections. Journal of European Baptist Studies 14: 22-33.

Bell D. (1992) Faces at the Bottom of the Well: The permanence of racism, New York.: Basic Books.

Berger A. (1995) Blind Men and Elephants: Perspectives on Humour, Brunswick: Transaction Publications.

Berger A. (2013) Forty five Ways to Make 'Em Laugh. Israeli Journal of Humor Research 3.

Bowers M. (2005) 'Ethnic Glue': Humour in Native American Literatures. In: Reichl S and Stein M (eds) Cheeky Fictions: Laughter and the Postcolonial. Amsterdam: Rodopi.

Bradbury S, van Sterkenburg J and Mignon P. (2015) The glass ceiling in European football: Levels of representation of visible ethnic minorities and women in leadership positions, and the experiences of elite level ethnic minority coaches. http://www.farenet.org/ FARE, pp1-20.

Burdsey D. (2011) That Joke Isn't Funny Anymore: Racial Microaggressions, Colour-Blind Ideology an the Mitigation of Racism in English Men's First Class Cricket. Sociology of Sport Journal 28: 261-283.

Carrington B. (2010) Race, sport and politics, London: Sage.

Charmaz K. (2005) Grounded Theory in the 21st Century. In: Denzin N and Lincoln Y (eds) The Sage Handbook of Qualitative Research. 3 ed. London: Sage, 507535.

Clarke L. (1998) Commentary. Journal of Psychiatry and Mental Health Nursing 5: 319-328.

Critchley S. (2002) On Humour, London: Routledge.

Delgado R. (1995) Storytelling for Oppositionists and Others: A plea for a narrative. In: Delgado R and Stefancic J (eds) Critical Race Theory: The cutting edge. Philadelphia: Temple University Press, 60-70.

Delgado R and Stefancic J. (1999) Critical Race Theory : the cutting edge, Philadelphia: Temple University Press.

Delgado R and Stefancic J. (2001) Critical Race Theory : An introduction, New York: New York University Press.

Duster T, Twine Warren JW and Winddance F. (1999) Race-ing research, researching race: Methodological dilemmas in Critical Race Studies.

Ford T, Richardson K and Petit W. (2015) Disparagement Humor and Prejudice: Contemporary theory and research. Humor 28: 171-186.

Freud S. (1991 [1960]) Jokes and their relation to the unconscious, New York: Penguin.

Gaggiano A. (2005) Using a comic vision to contend with tragedy: Three unusual African English novels. In: Reichl S and Stein M (eds) Cheeky Fictions: Laughter and the Postcolonial. Amsterdam: Rodopi.

Gratton C and Jones I. (2004) Research Methods for Sport Studies, London: Routledge. 
Gunaratnam Y. (2003) Researching 'Race' and Ethnicity: Methods, Knowledge and Power, London: Sage.

Gunn Allen P. (1992) The Sacred Hoop, Boston: Beacon Press.

Holland B. (1997) Surviving leisure time racism: the burden of racial harassment on Britain's black footballers. Leisure Studies 16: 261-277.

hooks b. (1989) Talking Back: thinking feminist, thinkig black, Boston: South End Press.

Hughey M. (2011) Backstage Discourse and the Reproduction of White Masculinities. Sociological Quarterly 52: 132-153.

Hylton K. (2012) Talk the Talk, Walk the Walk: Defining Critical Race Theory in Research. Race, Ethnicity and Education 15: 23-41.

Hynes M and Scott S. (2015) Black-faced, red faces: the potentials of humour for anti-racist action. Ethnic and Racial Studies: 1-18.

Jones RL. (2002) The Black Experience Within English Semiprofessional Soccer. Journal of Sport and Social Issues 26: 47-66.

King C. (2004) Offside Racism: Playing the White man, Oxford: Berg.

King CR. (2006) Defacements/Effacements Anti-Asian (American) Sentiment in Sport. Journal of Sport \& Social Issues 30: 340-352.

Lockyer S and Pickering M. (2005) Beyond a Joke: The limits of humour. Houndsmill: Palgrave Macmillan.

McNair J. (2008) "I May be Crackin', But Um Fackin'": Racial humour in The Watson's Go to Birmingham-1963. Children's Literature in Education 39: 201212.

Mulkay M. (1988) On Humour: It's nature and place in modern society, Cambridge: Polity Press.

Muller F, van Zoonen L and de Roode L. (2007) Accidental Racists: Expereinces and Contradictions of Racism in local Amsterdam Soceer Fan Culture. Soccer and Society 8.

Ostrower C. (2015) Humour as Defense Mechanism. Interpretaion: A Journal of Bible and Theology 69: 183-195.

Perakyla A. (2005) Analyzing Talk and Text. In: Denzin N and Lincoln Y (eds) The Sage Handbook of Qualitative Research. London: Sage.

Picca LH and Feagin JR. (2007) Two-faced racism : Whites in the backstage and frontstage, New York; London: Routledge.

Reid I. (2015) Just a wind-up? Ethnicity, religion and prejudice in Scottish footballrelated comedy. International Review for the Sociology of Sport 50: 227-245.

Richardson J. (2006) Analysising Newspapers: An approach from critical discourse ananlysis, Basingstoke: Palgrave Macmillan.

Robidoux M. (2004) Narratives of Race Relations in Southern Alberta: An examination of conflicting sporting practices. Sociology of Sport 21: 287-301.

Robidoux M. (2012) Stickhandling through the margins: First nations hockey in Canada, Toronto: University of Toronto Press.

Shaw S. (2006) Scratching the Back of "Mr X": Analyzing Gendered Social Processes in Sport Organizations. Journal of Sport Management 20: 510-534.

Snyder E. (1991) Sociology of Sport and Humour. International Review for the Sociology of Sport 26: 119-131.

Sue D. (2010) An Introduction. In: Sue D (ed) Microaggressions, Marginality, and Oppression. New Jersey: John Wiley and Sons, Inc. 
Sullivan P. (2013) Humor styles as a predictor of satisfaction within sport teams. Humor 26: 343-349.

Sullivan S and Tuana N. (2007) Race and epistemologies of Ignorance. Albany: State University of New York Press.

Vizenor G. (1994) Trickster Discourse: Comic and tragic themes in Native American Literature. In: Lindquist M and Zanger M (eds) Buried Roots and Indestructible Seeds: The survival of American Indian life in story, history, and spirit. Wisconsin: University of Wisconsin.

Watson C. (2015) A Sociologist Walks into a Bar (and Other Academic Challenges): Towards a methodology of humour. Sociology 49: 407-421.

Weaver S. (2010a) Developing a rhetorical analysis of racist humour: examining anti-black jokes on the Internet. Social Semiotics 20: 535-555.

Weaver S. (2010b) The 'Other' laughs back: Humour and resistance in anti-racist comedy. Sociology 44: 31-48.

Weaver S. (2011a) Jokes, rhetoric and embodied racism: a rhetorical discourse analysis of the logics of racist jokes on the internet. Ethnicities 0: 1-23.

Weaver S. (2011b) The Rhetoric of Racist Humour, Farnham: Ashgate.

Wilkins J and Eisenbraun A. (2009) Humor Theories and the Physiological Benefits of Laughter. Holistic Nursing Practice: 349-354.

Yosso T. (2005) Whose culture has capital? A critical race theory discussion of community cultural wealth. Race Ethnicity and Education 8: 69-91.

\section{Notes}

i The terms 'Black' and 'White' are used in upper case to denote two socially constructed racialised identities.

ii In some cases the use of patois infused some of the conversations and required interpretation.

iii The UEFA B license is the third highest level coaching award in European football. Second is the UEFA A, followed by the final Pro License.

iv Lilleshall is a Sport England national sports centre. 